\title{
Association between hospital emergency visits for asthma and air pollution in Valencia, Spain
}

\author{
José María Tenías, Ferran Ballester, María Luisa Rivera
}

\begin{abstract}
Objective-To assess the short term effect of concentrations of black smoke, sulphur dioxide $\left(\mathrm{SO}_{2}\right)$, nitrogen dioxide $\left(\mathrm{NO}_{2}\right)$ and ozone $\left(\mathrm{O}_{3}\right)$ in ambient air on emergency room visits for asthma in the city of Valencia, Spain during the period 1994-5. Methods-Ecological study with time series data and application of Poisson regression. Associations between number of daily emergency visits in a city's hospital and concentrations of air pollutants were analysed taking into account potential confounding factors by the standardised protocol of the air pollution and health: a European approach (APHEA) project.
\end{abstract}

Results-Mean (range) daily number of emergency room visits for asthma was 1 (0-5). Concentrations of all pollutants studied remained within current air quality standards. The association between an increase of $10 \mu \mathrm{g} / \mathrm{m}^{3}$ in ambient air pollution and asthma, measured as a relative risk (RR) of emergency visits, was significant for $\mathrm{NO}_{2} 24$ hour mean (lag 0, RR $1.076,95 \%$ confidence interval $(95 \% \mathrm{CI})$ 1.020 to 1.134$), \mathrm{NO}_{2}$ hour maximum (lag 0 , RR $1.037,95 \%$ CI 1.008 to 1.066 ), and $O_{3}$ hour maximum (lag 1, RR 1.063, CI 95\% 1.014 to 1.114). The association was not significant for $\mathrm{SO}_{2}$ or for black smoke during the period analysed. The effects were not significantly different for the time of year, cold months (November to April), or warm months (May to October).

Conclusions-Current concentrations of ambient air pollution in Valencia are significantly associated with emergency room visits for asthma. This association is high and more consistent for $\mathrm{NO}_{2}$ and $\mathrm{O}_{3}$ than for particulate matter and $\mathrm{SO}_{2}$ (classic pollutants).

(Occup Environ Med 1998;55:541-547)

Keywords: air pollution; asthma; emergency hospital admissions

An increase in the prevalence, use of medical care, and mortality from asthma has been reported in the United States and other western countries. ${ }^{1}$ In Spain the prevalence of asthmatic symptoms is estimated to be $5 \%$ $15 \%$ for subjects of $20-44$ years of age. ${ }^{2}$ Unlike other illnesses, the environmental determinants of asthma are less clear than are the biological factors, with research conducted on the role played by smoking, diet, viral respiratory infections, and both outdoor and indoor air pollution.

Studies which research the role of air pollution on asthma may be experimental, prospective (of the panel type), or community based. The first two of these contribute information on the physiopathological, functional, and clinical changes associated with controlled exposure (experimental) or not (panel studies) of the pollutants. In this way, ozone $\left(\mathrm{O}_{3}\right)$, particulate matter, and sulphur dioxide $\left(\mathrm{SO}_{2}\right)$ have shown their capacity to cause structural changes in airways and show a greater effect in asthmatic people, including a greater response to allergens. ${ }^{4}$ For nitrogen dioxide $\left(\mathrm{NO}_{2}\right)$, it has recently been shown that there is greater reactivity to the house dust mite in patients with mild asthma after exposure in habitual domestic concentrations ${ }^{56}$ clarifying in part the obscure relation between this pollutant and allergic asthma. ${ }^{7}$ Among epidemiological community based studies, ecological time series studies predominate; in these, the effect of air pollution on different indicators is related. The emergency visits for asthma are considered as an indicator of severity or poor control of the illness. Bates ${ }^{8}$ placed emergency visits in an intermediate position among health indicators which may be affected by air pollution (symptoms, spirometrical variations, medical visits, hospital emergencies, hospital admissions, mortality).

Few epidemiological studies have analysed the impact of air pollution on asthma emergencies. In general, they found a significant association between some of the pollutants studied and the number of emergency visits for asthma. ${ }^{9-16}$ However, in some of these studies no significant association has been found for any of the pollutants studied-namely, $\mathrm{O}_{3},{ }^{911}$ $\mathrm{NO}_{2},{ }^{10}{ }^{12}$ and $\mathrm{SO}_{2}{ }^{9}{ }^{11} 16$ This reflects the difficulties implied in identifying the individual effect of each pollutant.

The objective of this study was to assess the relation between daily concentrations of ambient air pollution and the number of emergency visits for asthma in a hospital in the city of Valencia.

\section{Methods}

DESIGN

The study is an ecological time series analysis, in which the relation between ambient air pollution and daily variations in the number of emergency room visits for asthma is explored.

\section{STUDY AREA}

The city of Valencia has an average population of over 750000 (census 1991). Its climate is that known as mesothermal (temperate). The
Accepted

25 February 1998 


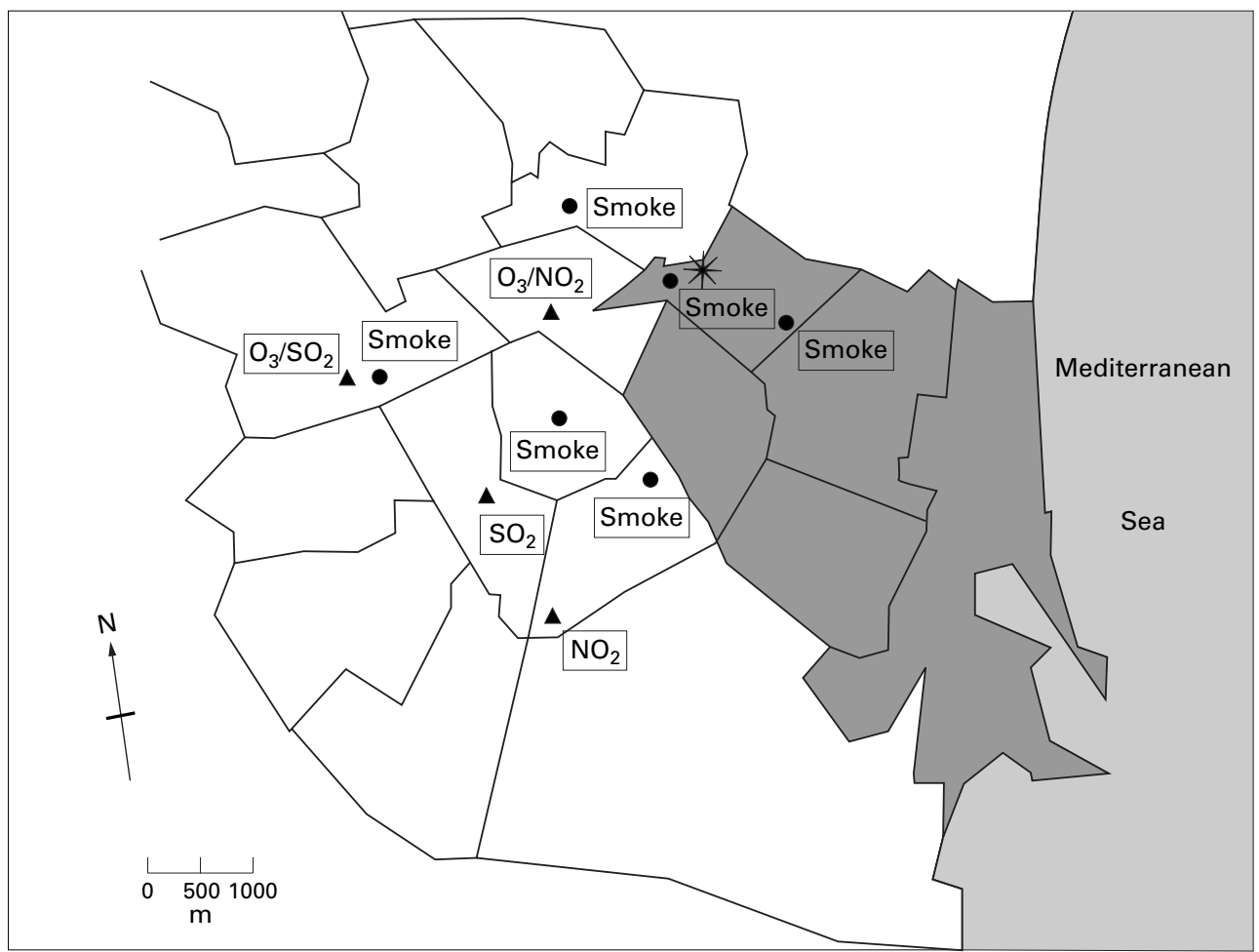

Figure 1 Map of municipal districts of Valencia, Spain. Location of manual (circles) and automatic (triangles) air pollution samplers and weather station (star) included in the study. The shaded area represents the catchment area of Hospital Clinico Universitario.

main sources of pollution are caused by motor vehicle emissions. In this study we analysed the relation between air pollution and emergency visits for asthma in one of the four large city hospitals (Hospital Clínic Universitari, HCU). This hospital has a catchment area covering part of the city with over 200000 inhabitants. The access to the emergency department is universal under the national healthcare system.

\section{DATA COLLECTION}

We collected all cases of asthma in residents of the catchment area, aged over 14, who made daily visits to the emergency department of the hospital over a period of 3 years (1 January 1993 to 31 December 1995). Cases of asthma in people living outside the city were excluded. The identification of cases of asthma was conducted by revision of the emergency department medical records. The method of data collection has been validated and widely documented. ${ }^{17}$

Briefly, this consisted in the identification, within the diagnosis section, of any of the terms selected by consensus, included in a list of synonyms of asthma (asthma, severe asthma attack, asthmatic bronchitis, spastic bronchitis, bronchial hyperreactivity, asthmatic status, wheezing, and bronchospasm), with the remaining records being revised in any doubtful cases. The identification was carried out by two trained observers (experienced nurses). The reliability of the results was good ( $\kappa$ indexes for agreement within an observer of 0.79 and 0.91 ; 0.87 for agreement between observers). ${ }^{18}$

Data on ambient air pollution were obtained from the city's surveillance network. This consists of 14 manual samplers and five automatic stations. The data from the manual network were available for the period 1993-5. From this network the 24 hour average $(24 \mathrm{~h})$ smoke concentrations were obtained (black smoke, reflectometry method). The automatic network did not have data available from 1993 but it did have some for 1994 and 1995. From this network the 24 hour mean $\mathrm{NO}_{2}$ (chemiluminiscence) and $\mathrm{SO}_{2}$ (ultraviolet fluorescence) and hourly maximum (1 hour) ozone $\left(\mathrm{O}_{3}\right.$ ultraviolet absorption), $\mathrm{NO}_{2}$, and $\mathrm{SO}_{2}$ were used. We only included in the study the data from those stations with $<25 \%$ of days with missing values. Under these criteria, data were included from six manual samplers and two automatic stations for each contaminant from the network (fig 1). The correlations between the measurements at different stations were from 0.404 to 0.680 for black smoke, 0.489 for $\mathrm{SO}_{2} 1$ hour, 0.489 for $\mathrm{SO}_{2} 24$ hour, 0.593 for $\mathrm{NO}_{2} 1$ hour, 0.871 for $\mathrm{NO}_{2} 24$ hour, and 0.753 for $\mathrm{O}_{3} 1$ hour.

Daily meteorological data (temperature and relative humidity) were obtained at the city's weather station in the Meteorological Centre of Valencia. The cases of influenza occurring weekly were obtained from the registers of the obligatory declared diseases system. Holidays were also taken into account (calendar), as well as the period of strike action by medical staff, which took place in May 1995. Further information on ambient air pollution, meteorological information, and influenza data have been published elsewhere. ${ }^{19}$

\section{DATA ANALYSIS}

The two main limitations in the interpretation of ecological time series studies are the differences in statistical methods used and the 
type of confounding factors taken into account. Goldsmith et $a l^{20}$ summarise them into three groups: geophysical factors (annual cycles and seasonality in our model); meteorological factors (temperature, humidity); and sociocultural factors (days of the week, holidays, strikes). An effort has recently been made to reach consensus and homogenisation with the creation of the air pollution and health: a European approach (APHEA) project (air pollution and health, a European approach). ${ }^{21}$ The general lines of the analysis strategy matched those adopted by the APHEA project. ${ }^{22}$

The effects of variations in concentrations of air pollutants on emergency cases of asthma were estimated by means of Poisson autoregressive regression modelling. The analysis was conducted in two phases; in the first one a core model was constructed in which the main confounding variables of the relation between air pollutants and asthma were included: seasonality (sinusoidal terms), temperature and humidity, long term trend variables (trend variable for the whole period and indicator variables of year), calendar effects (day of the week and holiday), and influenza indices. After the model was constructed and checked for the presence of residual autocorrelation we included pollutants in the model estimating their effect. Following the APHEA protocol ${ }^{22}$ we analysed the single and cumulative effects on the

Table 1 Daily mean and percentiles for study variables (Valencia, period 1994-5)

\begin{tabular}{|c|c|c|c|c|c|c|c|c|}
\hline & \multicolumn{6}{|c|}{ All year } & \multirow{2}{*}{$\begin{array}{l}\text { Warm } \\
\text { months } \\
\text { Mean }\end{array}$} & \multirow{2}{*}{$\begin{array}{l}\text { Cold } \\
\text { month } \\
\text { Mean }\end{array}$} \\
\hline & Mean & $P_{25}$ & $P_{50}$ & $P_{75}$ & $P_{95}$ & $n$ & & \\
\hline Cases of asthma & 1.0 & 0 & 1 & 2 & 3 & 730 & 0.9 & 1.1 \\
\hline Mean temperature $\left({ }^{\circ} \mathrm{C}\right)$ & 18.8 & 14.5 & 18.4 & 22.9 & 27.6 & 730 & 23.0 & 14.5 \\
\hline Relative humidity (\%) & 62.7 & 53.0 & 64.7 & 73.3 & 82.6 & 730 & 65.9 & 59.4 \\
\hline Smoke & 38.8 & 25.6 & 35.2 & 47.7 & 77.1 & 730 & 31.3 & 46.5 \\
\hline $\mathrm{NO}_{2} 24 \mathrm{~h}$ & 57.7 & 40.2 & 55.6 & 71.9 & 88.1 & 725 & 59.4 & 55.9 \\
\hline $\mathrm{NO}_{2} 1 \mathrm{~h}$ & 100.1 & 71.0 & 95.5 & 121.8 & 152.6 & 725 & 102.8 & 97.3 \\
\hline $\mathrm{O}_{3} 1 \mathrm{~h}$ & 62.8 & 44.0 & 62.4 & 78.6 & 94.4 & 718 & 74.0 & 51.4 \\
\hline $\mathrm{SO}_{2} 24 \mathrm{~h}$ & 26.6 & 17.9 & 26.2 & 34.3 & 42.6 & 722 & 21.7 & 31.7 \\
\hline $\mathrm{SO}_{2} 1 \mathrm{~h}$ & 56.3 & 36.3 & 52.2 & 72.2 & 95.2 & 722 & 48.2 & 64.6 \\
\hline Influenza & 161.6 & 56 & 121 & 226 & 427 & 730 & 70.4 & 254.3 \\
\hline
\end{tabular}

All pollutants measured in $\mu \mathrm{g} / \mathrm{m}^{3}$.

Table 2 Pearson correlation coefficients between mean temperature, relative humidity, and pollutants (Valencia, period 1994-5)

\begin{tabular}{|c|c|c|c|c|c|c|c|}
\hline & $\begin{array}{l}\text { Mean } \\
\text { temperature }\end{array}$ & $\begin{array}{l}\text { Relative } \\
\text { humidity }\end{array}$ & Smoke & $\mathrm{NO}_{2}(24 h)$ & $\mathrm{NO}_{2}(1 h)$ & $O_{3}(1 h)$ & $\mathrm{SO}_{2}(24 h)$ \\
\hline $\begin{array}{l}\text { Relative } \\
\text { humidity }\end{array}$ & 0.141 & 1 & & & & & \\
\hline Smoke & -0.449 & 0.040 & 1 & & & & \\
\hline $\mathrm{NO}_{2}(24 \mathrm{~h})$ & $-0.029^{\star}$ & 0.142 & 0.288 & 1 & & & \\
\hline $\mathrm{NO}_{2}(1 \mathrm{~h})$ & $0.008^{\star}$ & 0.119 & 0.246 & 0.932 & 1 & & \\
\hline $\mathrm{O}_{3}(1 \mathrm{~h})$ & 0.446 & -0.431 & -0.551 & -0.304 & -0.192 & 1 & \\
\hline $\mathrm{SO}_{2}(24 \mathrm{~h})$ & -0.479 & -0.174 & 0.687 & 0.265 & 0.199 & -0.431 & 1 \\
\hline $\mathrm{SO}_{2}(1 \mathrm{~h})$ & -0.352 & -0.080 & 0.617 & 0.261 & 0.201 & -0.304 & 0.905 \\
\hline
\end{tabular}

Table 3 Relation between ambient air pollution and emergency room visits for asthma in the Hospital Clinico of Valencia, 1994-5

\begin{tabular}{lllll}
\hline Pollutant & Lag & Whole period & Cold months & Warm months \\
\hline $\mathrm{Smoke}$ & 0 & $1.025(0.981$ to 1.072$)$ & $1.036(0.984$ to 1.089$)$ & $1.007(0.909$ to 1.116$)$ \\
$\mathrm{NO}_{2}(24 \mathrm{~h})$ & 0 & $1.076(1.020$ to 1.134$)$ & $1.083(1.022$ to 1.148$)$ & $1.066(0.989$ to 1.149$)$ \\
$\mathrm{NO}_{2}(1 \mathrm{~h})$ & 0 & $1.037(1.008$ to 1.066$)$ & $1.034(1.004$ to 1.066$)$ & $1.044(1.002$ to 1.088$)$ \\
$\mathrm{O}_{3}(1 \mathrm{~h})$ & 1 & $1.063(1.014$ to 1.114$)$ & $1.035(0.966$ to 1.110$)$ & $1.083(1.024$ to 1.146$)$ \\
$\mathrm{SO}_{2}(24 \mathrm{~h})$ & 0 & $1.050(0.973$ to 1.133$)$ & $1.032(0.937$ to 1.138$)$ & $1.070(0.936$ to 1.224$)$ \\
$\mathrm{SO}_{2}(1 \mathrm{~h})$ & 0 & $1.027(0.998$ to 1.057$)$ & $1.018(0.980$ to 1.057$)$ & $1.038(0.990$ to 1.090$)$
\end{tabular}

Relative risks (95\% CI) have been calculated for an increase of $10 \mu \mathrm{g} / \mathrm{m}^{3}$ in the concentrations of each pollutant. number of asthma emergencies for each pollutant up to the third lag (fifth for ozone).

The dose-response relations between pollutants and asthma were assessed with the introduction of indicator variables representing the quartiles of each pollutant with the first quartile as the reference level.

\section{Stratified and effect modification analysis by} period

When there was no significant association overall two separate models were constructed, one for the coldest time of year (November to April) and another for the warmest (May to October). If a significant association was found we tested for a different slope in both periods with an interaction term of the pollutant and the categorised semester variable $(0=$ cold semester; $1=$ warm semester) ${ }^{23}$

\section{Confounding and interaction between pollutants}

Once the effect of each air pollutant on cases of asthma had been assessed in isolation, we proceeded to enter the rest of the pollutants in the model according to the following criteria: we only introduced a maximum of two pollutants at a time (to avoid multicollinearity and interpretation problems) and the averaging time, daily average or maximum hourly concentration was, when possible (black smoke was only available as daily average concentrations), the same for both, as the different representative measurements could lead to spurious changes in regression coefficients. ${ }^{24}$ We assessed the interaction by means of the introduction of multiplicative terms between the concentration of air pollutant of interest and a dummy variable for the air pollutant modifier $(0=$ values below the median; $1=$ values above the median). The presence of interaction was evaluated with statistical criteria. ${ }^{22}$

\section{Results}

Table 1 shows the distribution of cases of asthma, concentrations of pollutants, and meteorological variables for the period of analysis, 1994-5. In total 734 cases of asthma occurred over the two years (an average of one case daily and a maximum of five). These showed a Poisson distribution (KolmogorovSmirnoff goodness of fit test, $\mathrm{p}=0.65$ ).

Table 2 shows the correlation between the different pollutants and meteorological variables. Sulphur dioxide and smoke show close positive intercorrelation, and both also show strong negative association with temperature. The association between both $\mathrm{SO}_{2}$ and smoke and $\mathrm{NO}_{2}$ is positive, but this association is weaker than that between $\mathrm{SO}_{2}$ and smoke. Ozone shows negative correlation with other pollutants and positive correlation with temperature.

The associations between concentrations of pollution and cases of asthma were positive and significant at the 5\% level for $\mathrm{NO}_{2}$ and $\mathrm{O}_{3}$ (table 3). Sulphur dioxide and black smoke had a positive association but this did not reach significance. However, black smoke was significantly associated with emergency visits for asthma when the period of analysis was 


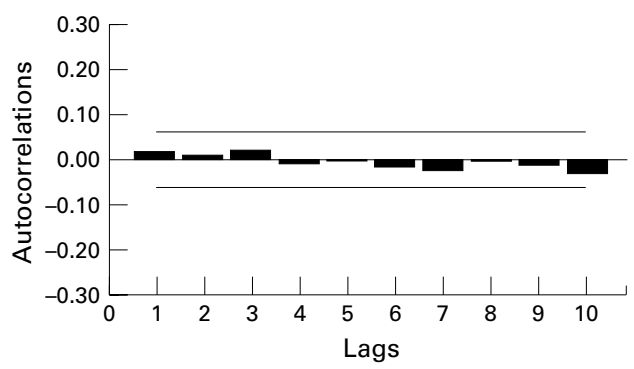

Figure 2 Autocorrelation functions of residuals of the core models of the Poisson regression before inclusion of pollutants.

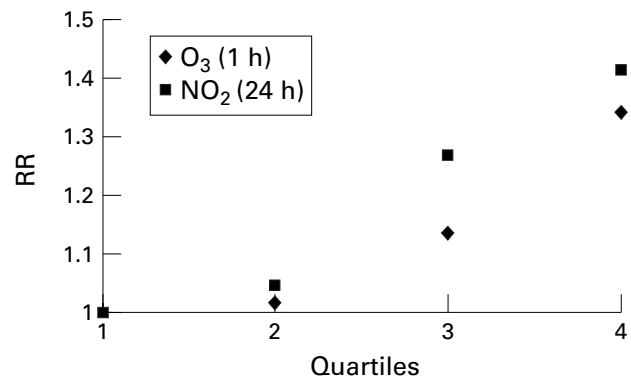

Figure 3 Air pollution and emergency hospital visits for asthma, Valencia, Spain, 1994-5. Dose-response relation for $\mathrm{O}_{3} 1$ hour and $\mathrm{NO}_{2} 24$ hour is shown as relative risks (RRs) for different quartiles of pollutant.

extended to three years, 1993-5 (relative risk (RR) for an increase of $10 \mu \mathrm{g} / \mathrm{m}^{3}$, lag 01.041 , $95 \%$ CI 1.004 to 1.080 ). In no case did we find a negative significant effect for the lags studied. The results of table 3 correspond with the lags with the higher significant estimates for each pollutant. Smoke showed a greater effect in cold months than in warm months, the opposite to $\mathrm{O}_{3}$, but $\mathrm{NO}_{2}$ did not show important differences between the seasons. However, in no instance was the modification of effect due to time of the year significant.

The core model was made up of three sinusoidal terms, average temperature and humidity (lag 1), and one indicator variable for each year. Both climatological variables remained in the core model despite the fact that they were not significantly associated with asthma. The autocorrelation functions of residuals showed a good control of raw series serial correlation (fig 2).

Figure 3 shows the RR adjusted for quartiles of the pollutants with the greatest effect $\left(\mathrm{O}_{3} 1\right.$ hour and $\mathrm{NO}_{2} 24$ hour). For both pollutants, the $\mathrm{RR}$ of each quartile are placed above the no effect line (RR 1) and there is a monotonic increase in the risk. Also we can see that the risk ratio associated with an increase in the interquartile range was higher for $\mathrm{NO}_{2}$ than $\mathrm{O}_{3}$.

Figure 4 shows the confounding capacity between the different pollutants. Both $\mathrm{O}_{3}$ and $\mathrm{NO}_{2}$ have been shown to vary least among the pollutants. In the extreme case of including all four in the same model, $\mathrm{O}_{3}$ and $\mathrm{NO}_{2}$ did not undergo important changes, the effect of smoke fell slightly, and the effect of $\mathrm{SO}_{2}$ was inverted, proving that it is the most vulnerable (data not shown). None of them showed a significant interaction on the effect of the rest according to statistical criteria.

\section{Discussion}

In this work we found a positive and significant association between ambient concentrations of $\mathrm{NO}_{2}$ and $\mathrm{O}_{3}$ with the number of emergency visits for asthma attended daily in Valencia's Hospital Clínic Universitari in 1994-5. The

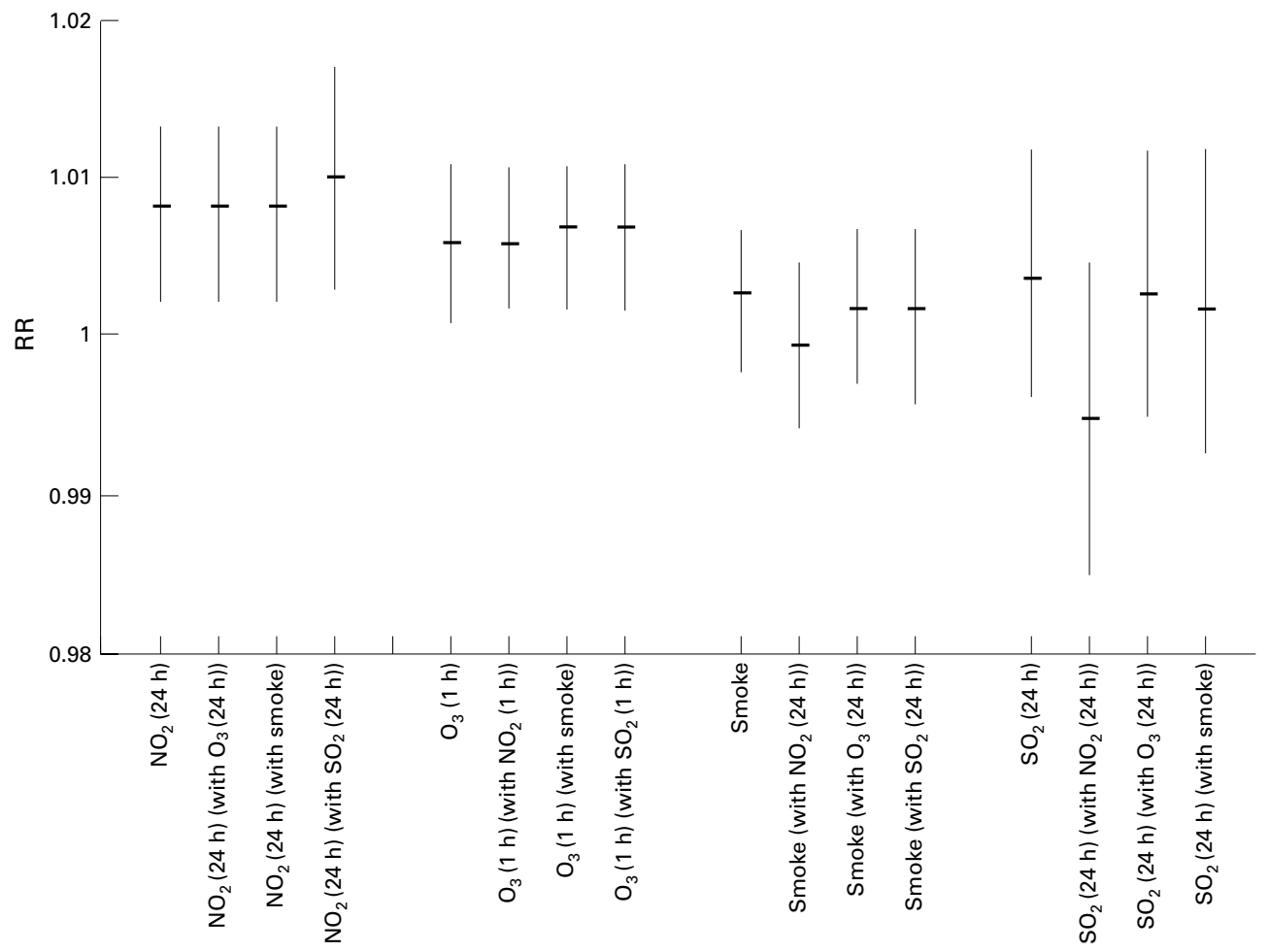

Figure 4 Relative risks (95\% Cls) for an increase in $1 \mu \mathrm{g} / \mathrm{m}^{3}$ of the different air pollutants when they are entered alone into the core model and when another pollutant is added, Valencia, 1994-5. 
association with $\mathrm{SO}_{2}$ and black smoke, although positive, did not reach significance. The greatest effect found was for $\mathrm{NO}_{2}$ and $\mathrm{O}_{3}$. An increase in the concentrations of these pollutants of $10 \mu \mathrm{g} / \mathrm{m}^{3}$ was associated with an increase in the number of emergency visits for asthma of $7.6 \%$ and $6.3 \%$ respectively. These results are similar to those described in other studies which detected a significant influence of concentrations of ambient pollution on the use of hospital emergency services. However, there are divergences over the main pollutants responsible for this effect.

OZONE

In the city of Barcelona, with similar climatic conditions to those of Valencia, the same pollutants and the same dependent variable were analysed by Castellsague et al. ${ }^{9}$ In that study a positive significant association was found for $\mathrm{NO}_{2}$ and black smoke although not for $\mathrm{O}_{3}$ and $\mathrm{SO}_{2}$. The RRs for the same increase of air pollutants were lower than those found in our study. The main differences correspond to the effect of $\mathrm{O}_{3}$, with a negative (although not significant) association for the summer months in Barcelona. The greatest concentrations of $\mathrm{O}_{3}$ occur in the warmest time of year due to a greater oxidation of other pollutants by sunlight. In our case we have verified a greater effect of $\mathrm{O}_{3}$ in the warm semester, with an $8.3 \%$ increase in emergency visits. This effect was lower $(3.5 \%)$ during the coldest time of year, but not significant.

Schwartz et $a l^{11}$ in Seattle found a negative (although not significant) effect, RR 0.97 (95\% CI 0.89 to 1.05 ) for an increase of $30 \mu \mathrm{g} / \mathrm{m}^{3}$. Ozone was monitored from May to September. As the concentrations were not shown we cannot assess whether the effect could be related to low concentrations of pollutant.

Bates et $a l^{10}$ studied the relation between air pollution and emergency visits for asthma in nine Vancouver hospitals without finding a measurable effect of $\mathrm{O}_{3}$, due according to the authors, to its association with temperature. However, seasonality was not monitored within each season, which would lead to a possible overestimation of the effects in winter and an underestimation in summer. ${ }^{24}$ We have analysed the effects of $\mathrm{O}_{3}$ in both seasons by introducing an interaction term of this pollutant and the seasonal variable maintaining sinusoidal terms, thereby continuing to monitor the seasonality of the series. The stratified analysis by season led us to practically the same results.

In New Jersey the influence of $\mathrm{O}_{3}$ was assessed between May and August on emergency visits for asthma in nine city hospitals. ${ }^{12}{ }^{13}$ In both studies a significant effect was found for $\mathrm{O}_{3}$. The concentrations of this air pollutant were placed above those usually found in Valencia (average values of about 95 $\mu \mathrm{g} / \mathrm{m}^{3}$ ) although they are not directly comparable as they used a different type of measurement (average hourly concentrations for the period between 10 and 15 hours).

Recently, Stieb et $a l^{15}$ have detected a significant association between $\mathrm{O}_{3}$ and asthma emergency visits in Saint John, New Brunswick,
Canada for 1984-92 (May-September). The frequency of asthma visits was $33 \%$ higher when the daily 1 hour maximum $\mathrm{O}_{3}$ concentration was $>75 \mathrm{ppb}\left(\right.$ about $\left.150 \mu \mathrm{g} / \mathrm{m}^{3}\right)$. The concentrations of $\mathrm{O}_{3}$ were similar to the ones registered in Valencia for the same period of the year. Unlike our study, the data collection was based on the patient's complaint and subsequently, sensitivity of detecting asthma was low (about 50\%). This fact makes direct comparison with our results difficult.

Despite the differences in results of the studies which assess emergency visits for asthma, when the dependent variable is hospital admissions they predominantly find positive effects. $^{25-28}$

\section{NITROGEN DIOXIDE}

Nitrogen dioxide is considered to be a precursor in the formation of $\mathrm{O}_{3}$. The main source of $\mathrm{NO}_{2}$ is from motor vehicle emissions ${ }^{29}$ although $\mathrm{NO}_{2}$ production from inside buildings is also important (above all from cookers and gas heaters). On an experimental level $\mathrm{NO}_{2}$ has been shown to be less reactive than $\mathrm{O}_{3}$, although it has been possible to show biological effects such as cellular dysfunction at the level of the bronchial epithelia. ${ }^{30}$ Clinically, the effects of $\mathrm{NO}_{2}$ on healthy subjects have not been conclusively demonstrated although in asthmatic people they seem to have a more prominent role. $^{7}$

There are few studies which have analysed the relation between concentrations of $\mathrm{NO}_{2}$ and emergency visits for asthma. ${ }^{9} 101214 \mathrm{~A}$ smaller effect from $\mathrm{NO}_{2}$ was found in the Barcelona study ${ }^{9}$ (an increase of over $2.8 \%$ in asthma visits for an increase of $10 \mu \mathrm{g} / \mathrm{m}^{3}$ ) and $\mathrm{NO}_{2}$ was also found to have a greater impact in winter than in summer.

Bates et $a l^{10}$ in Vancouver did not find a significant relation between $\mathrm{NO}_{2}$ and emergency visits for asthma but did find one with the total of respiratory diseases in people over 61 during the cold months. Weisel et $a l^{12}$ in New Jersey did not find a significant relation (although the size of the relation is not shown) and Kesten et $a l^{14}$ in Toronto found a positive and significant effect of average weekly concentrations of $\mathrm{NO}_{2}$ on weekly cases of emergency visits for asthma (the magnitude of the association was not shown) for the next week.

Both $\mathrm{NO}_{2}$ and $\mathrm{O}_{3}$ have shown a significant effect on emergency visits for asthma in Valencia. The fact that $\mathrm{NO}_{2}$ is one of the main precursors of $\mathrm{O}_{3}$ could be the reason for a possible mutual influence of its effects; however, we have been unable to detect any confounding effect as both maintained their RRs when they were entered together in the same model; nor have we detected any significant interaction. The lack of interaction may, however, be because the effects found are related to total oxidant concentration, rather than to one of these oxidant pollutants.

\section{PARTICULATE MATTER}

Levels of particulate matter were associated with emergency visits for asthma, although not significantly. However, when we analysed the 
three year series we obtained a significant effect that was higher in cold months (for an increase of $10 \mu \mathrm{g} / \mathrm{m}^{3}$, lag 0, RR $1.049,95 \%$ CI 1.008 to 1.093) than in warm months (lag 0, RR 1.011; $95 \%$ CI 0.936 to 1.093 ). Castellsague et $a l,{ }^{9}$ in Barcelona, also found a positive effect for black smoke although the greatest effect, unlike in our study, was shown in the summer months. In Valencia, concentrations of black smoke are higher in winter than in summer, but lower at all times than those of Barcelona, although the periods in question are different. Perhaps the slight variability of the concentrations of smoke in warm months in Valencia explains the fact that we did not detect a significant effect during this period, without disregarding other explanations (aerodynamic changes in particulate matter, influence of other pollutants). Schwartz et $a l^{11}$ in Seattle, a city with low concentrations of $\mathrm{PM}_{10}$ (inhaled particulate matter of $<10 \mu \mathrm{m}$ in diameter) find a positive and significant effect of this pollutant on emergency visits for asthma during the study period (1 year), and does not find a significant interaction effect relative to the time of year. In the studies carried out in New Jersey either the effect of particulate matter was not studied ${ }^{12}$ or it was carried out on non-daily measurements - that is, every six days ${ }^{13}$ - not finding a significant effect. In Ontario ${ }^{14}$ the effect was significant for two indices (pollution index and air quality index) including total suspended particles (TSP). Despite these findings the authors do not, unfortunately, show the effect per pollutant.

\section{SULPHUR DIOXIDE}

In a study published 12 years ago Goldstein and Weinstein ${ }^{16}$ did not find a significant effect between concentrations of $\mathrm{SO}_{2}$ and emergency visits in three municipal hospitals in the city of New York. In the rest of the studies similar to our own ${ }^{9-13}$ (except for that of Bates et al in Vancouver ${ }^{10}$ ) it has not been possible to show a significant effect of $\mathrm{SO}_{2}$. The high correlation between $\mathrm{SO}_{2}$ and particulate matter obstructs the isolation of the effects and therefore led some authors ${ }^{31}$ to conduct their studies in locations where $\mathrm{SO}_{2}$ is found at such low concentrations as not to raise any doubt about the part played by particulate matter.

In the confounding analysis, $\mathrm{SO}_{2}$ was the most affected by (or sensitive to) the presence of other pollutants, which may mean an even lower individual effect than that shown by its regression coefficient when it was the only pollutant in the model.

In this study the association between asthma visits was high and more consistent for $\mathrm{NO}_{2}$ and $\mathrm{O}_{3}$ than for particulate matter and $\mathrm{SO}_{2}$ (classic pollutants). Furthermore all pollutants studied, except smoke, showed a greater effect in warm months than in cold ones. In general, the concentrations of pollutants were moderate or even low for $\mathrm{SO}_{2}$ (over the whole period), smoke (during warm months), and $\mathrm{O}_{3}$ (during the cold months). This could partly explain the non-significant association when we carried out the analyses for the periods specific to these pollutants. It has been suggested that the greater effect of the pollutants during the warmer months could be a result of higher exposure based on modified activity patterns. ${ }^{32}$ This includes the fact that people spend more time outdoors and windows are left open longer, so the indoor concentrations are closer to those found outdoors.

We also consider the estimates found for $\mathrm{NO}_{2}$ and $\mathrm{O}_{3}$ to be important owing to the fact that more studies have concentrated on both mortality as the end point and on particulates and $\mathrm{SO}_{2}$ as the main pollutants. Furthermore, the main pollution source today is road traffic leading to high emissions to nitrogen compounds which in turn affect the $\mathrm{NO}_{2}$ and $\mathrm{O}_{3}$ concentrations. Whether to incorporate these findings in the monitoring of the pollutants in the air pollution control networks should be considered.

Identification of the models could affect the final results. We assessed the effect of the pollutants on emergency visits for asthma by constructing different core models, with the inclusion in one of them of all terms considered in our protocol. In all cases the results were similar; however, we choose the most parsimonious models due to the fact that they offered two advantages: fewer collinearity problems and in some cases, more precise estimations.

A limitation of this study, and of ecological studies in general, is due to the measurement of exposure, which prevents extrapolating the conclusions to an individual level. However, we are of the opinion that it is more important to assess the effect of exposure on a collective level as it is the only regulation subsidiary.

Another limitation could be the relatively small size of the population compared with the standard for recent publications of this type. In this situation, changes in the outcome variable would have a greater impact on the estimates. This fact may be an explanation of the large relative risks found.

The different geographical location of the sampling stations could be the cause of an underestimation or overestimation of the sample population's exposure. However, it is a practical impossibility to determine the ideal measurement, as the creation of pondered exposure variables would require knowledge of aspects such as the extent of contaminant dispersion, the number of people walking through the area as well as those who live there, the mean duration of exposure, etc. There is, therefore, no sound empirical basis for deciding what would be the ideal independent variable for use in studies of air pollution. If these measurement errors showed an effect it would take the form of a bias toward the null.

Despite these limitations we think that the relation found between ambient air pollution and asthma is not spurious as we have adjusted for those variables that may act as confounding factors. Furthermore, the temporal pattern seems to be compatible with the nature of the illness showing an immediate impact of air pollution on asthma.

In conclusion, the findings of this study show a positive relation between concentrations of ambient pollution and emergency visits for 
asthma, even by the standards considered as safe. ${ }^{33}{ }^{34}$ This could be relevant to public health policy due to the number of people exposed, the existence of high risk groups, and the possibility of introducing control measures.

This work was supported in part by grant 95/0050-02 from the Fondo de Investigaciones Sanitarias. We thank Toni Merelles and Julián González for their generous assistance in processing Sunyer for constructive comments on earlier drafts of this manuscript.

1 Weiss KB, Gergen PJ, Wagener DK. Breathing better or wheezing worse? The changing epidemiology of asthma
morbidity and mortality. Annu Rev Public Health 1993;14:491-513.

2 Grupo Español del Estudio Europeo del Asma. Estudio Europeo del Asma. Prevalencia de síntomas relacionados con el asma en cinco áreas españolas. Med Clin (Barc) 1995;104:487-92.

3 Newman-Taylor A. Environmental determinants of asthma. Lancet 1995;345:296-9.

4 Molfino NA, Wright SC, Katz I, et al. Effect of low concentrations of ozone on inhaled allergen responses in asthmatic subjects. Lancet 1991;338:199-203

5 Tunnicliffe WS, Burge PS, Ayres JG. Effect of domestic concentrations of nitrogen dioxide on airway responses to inhaled allergen in asthmatic patients. Lancet 1994;344: 1733-6.

6 Devalia JL, Rusznac C, Herdman MJ, et al. Effect of nitrogen dioxide and sulphur dioxide on airway response of mild asthmatic patients to allergen inhalation. Lancet 1994;344: 1668-71.

7 Antó JM, Sunyer J. Nitrogen dioxide and allergic asthma: starting to clarify an obscure association. Lancet 1995;345: $402-3$.

8 Bates DV. Health Indices of the adverse effects of air pollution: the question of coherence. Environ Res 1992;59: 336-49.

9 Castellsague J, Sunyer J, Sáez M, et al. Short-term association between air pollution and emergency room visits for asthma in Barcelona. Thorax 1995;50:1051-6.

10 Bates DV, Baker-Anderson M, Sizto R. Asthma attack periodicity: a study of hospital emergency visits in Vancouver. Environ Res 1990;51:51-70.

11 Schwartz J, Slater D, Larson TV, et al. Particulate air pollution and hospital emergency room visits for asthma in Seattle. Am Rev Respir Dis 1993;147:826-31.

12 Weisel CP, Cody RP, Lioy PJ. Relationship between summertime ambient ozone levels and emergency department visits for asthma in Central New Jersey. Environ Health Perspect 1995;103(suppl 2):97-102.

13 Cody RP, Weisel CP, Birsnbaum G, et al. The effect of ozone associated with summertime photochemical smog on the frequency of asthma visits to hospital emergency departfrequency of asthma visits to hospit

14 Kesten S, Szalai J, Dzyngel B. Air quality and the frequency of emergency room visits for asthma. Ann Allergy Asthma Inmunol 1995;74:269-73.

15 Stieb DM, Burnett RT, Beveridge RC, et al. Association between ozone and asthma emergency room visits in Sain John, New Brunswick, Canada. Environ Health Perspect 1996;104:1354-60.
16 Goldstein IF, Weinstein AL. Air pollution and asthma: effects of exposures to short-term sulphur dioxide peaks. Environ Res 1986;40:332-45.

17 Martínez F, Sunyer J, Antó JM. Reliability of a monitoring system for respiratory emergency room admissions. Eur Respir F 1993;6:337-41.

18 Merelles T. Estudio de fiabilidad y validez en la identificación de asma y EPOC en el Servicio de Urgencias del Hospital Clinico Universitario de Valencia IPublic Health Masters dissertation]. Valencia, Institut Valenciá d'Estudis en Salut Pública (IVESP), 1996.

19 Ballester F, Corella D, Pérez-Hoyos S, et al. Air pollution and mortality in Valencia, Spain: a study using the APHEA methodology. F Epidemiol Community Health 1996;50:52733.

20 Goldsmith JR, Friger MD, Abramson M. Associations between health and air pollution in time-series analyses. Arch Environ Health 1996;51:359-67.

21 Katsouyanni K, Zmirou D, Spix C, et al. Short-term effects of air pollution on health: a European approach using epidemiological time series data. Eur Respir f 1995;8:1030-8.

22 Kartsouyanni K, Schwartz J, Spix C, et al. Short term effects of air pollution on health: a European approach using epidemiologic time series data: the APHEA protocol. $\mathcal{f}$ Epidemiol Community Health 1996;50:S12-8.

23 Schwartz J, Spix C, Touloumi G, et al. Methodological issues in studies of air pollution and daily counts of deaths or hospital admissions. F Epidemiol Community Health 1996;50:S3-11.

24 Lipfert FW. A critical review of studies of the association between demands for hospital services and air pollution. Environ Health Perspect 1993;101:S229-68.

25 Bates DV, Sizto R. Air pollution and hospital admissions in Southern Ontario: the acid summer haze effect. Environ Res 1987;43:317-31.

26 Pönkä A, Virtanen M. Asthma and ambient air pollution in Helsinki. F Epidemiol Community Health 1996; 50:S59-62.

27 Burnett RT, Dales RE, Raizenne ME, et al. Effects of low ambient levels of ozone and sulfates on the frequency of respiratory admissions to Ontario hospitals. Environ Res 1994;65:172-94.

28 Thurston GD, Ito K, Hayes CG, et al. Respiratory hospital admissions and summertime haze air pollution in Toronto, Ontario: consideration of the role of acid aerosols. Environ Res 1994;65:271-90.

29 A Committee of the Environmental and Occupational Health Assembly of the American Thoracic Society. Health effects of outdoor air pollution. Am 7 Respir Crit Care Med 1996;153:3-50.

30 Devalia JL, Sapsford RI, Cundell DR, et al. Human bronchial epithelial cell dysfunction following in vitro exposure to nitrogen dioxide. Eur Respir f 1993;6:1308-16.

31 Schwartz J. Air pollution and hospital admissions for respiratory disease. Epidemiology 1996;7:20-8.

32 Katsouyanni K. Health effects of air pollution in southern Europe: are there interacting factors?. Environ Health Perspect 1995;103(suppl2):23-7.

33 World Health Organization. Air quality guidelines for Europe. Copenhagen: WHO, 1987. (WHO Regional Publications European Series No 23.)

34 US Environmental Protection Agency. National Air Quality and emissions trends. Office of air quality planning and standards, 1991. Research Triangle Park, NC: USEPA, 1991. (450-R-92-001.) 